\title{
Simultaneous isolation of pure and intact chloroplasts and mitochondria from moss as the basis for sub-cellular proteomics
}

\author{
Erika G. E. Lang - Stefanie J. Mueller • Sebastian N. W. Hoernstein • \\ Joanna Porankiewicz-Asplund · Marco Vervliet-Scheebaum • Ralf Reski
}

Received: 16 July 2010/Revised: 16 September 2010/Accepted: 24 September 2010/Published online: 20 October 2010

(C) The Author(s) 2010. This article is published with open access at Springerlink.com

\begin{abstract}
The moss Physcomitrella patens is increasingly being used as a model for plant systems biology studies. While genomic and transcriptomic resources are in place, tools and experimental conditions for proteomic studies need to be developed. In the present study we describe a rapid and efficient protocol for the simultaneous isolation of chloroplasts and mitochondria from moss protonema. Routinely, 60-100 $\mu \mathrm{g}$ mitochondrial and 3-5 mg chloroplast proteins, respectively, were obtained from $20 \mathrm{~g}$ fresh weight of green moss tissue. Using 14 plant compartment marker antibodies derived from seed plant and algal protein sequences, respectively, the evolutionary conservation of the compartment marker proteins in the moss was
\end{abstract}

Communicated by P. Kumar.

E. G. E. Lang and S. J. Mueller contributed equally to this work.

Electronic supplementary material The online version of this article (doi:10.1007/s00299-010-0935-4) contains supplementary material, which is available to authorized users.

E. G. E. Lang · S. J. Mueller · S. N. W. Hoernstein .

M. Vervliet-Scheebaum · R. Reski $(\varangle)$

Plant Biotechnology, Faculty of Biology, University of Freiburg,

Schaenzlestr. 1, 79104 Freiburg, Germany

e-mail: Ralf.Reski@biologie.uni-freiburg.de

E. G. E. Lang · M. Vervliet-Scheebaum - R. Reski

Freiburg Initiative for Systems Biology (FRISYS),

University of Freiburg, Schaenzlestr. 1, 79104 Freiburg,

Germany

S. J. Mueller · R. Reski

Spemann Graduate School of Biology and Medicine (SGBM),

University of Freiburg, Albertstr. 19A, 79104 Freiburg, Germany

J. Porankiewicz-Asplund

Agrisera AB, Box 57, 91121 Vännäs, Sweden demonstrated and purity and intactness of the extracted organelles confirmed. This isolation protocol and these validated compartment markers may serve as basis for subcellular proteomics in $P$. patens and other mosses.

Keywords Organelles · Compartment marker · Chloroplast proteins · Mitochondrial proteins .

Physcomitrella $\cdot$ Bryophyte

\begin{tabular}{|c|c|}
\hline \multicolumn{2}{|l|}{ Abbreviations } \\
\hline AOX & Alternative oxidase \\
\hline Arf & ADP-ribosylation factor \\
\hline Csp41b & Ribosome associated endonuclease \\
\hline $\operatorname{cox}$ & Cytochrome $c$ oxidase \\
\hline CPX1 & Coproporphyrinogen III oxidase \\
\hline CRD1 & $\begin{array}{l}\text { Cyanobacterial homolog of plant CHL } 27 \\
\text { cyclase }\end{array}$ \\
\hline Cyt $f$ & $\begin{array}{l}\text { Cytochrome } f \text { protein of thylakoid } \\
\text { cytochrome b6/f-complex }\end{array}$ \\
\hline GLN & Glutamine synthetase \\
\hline Hsp70b & Stromal alfa-heat shock protein 70 \\
\hline Lhcb2 & $\begin{array}{l}\text { Light harvesting complex II chlorophyll } \\
\text { a/b-binding protein }\end{array}$ \\
\hline PsaD & Photosystem I reaction centre subunit II \\
\hline PsbP & $\begin{array}{l}23 \mathrm{kDa} \text { protein of the oxygen evolving } \\
\text { complex of photosystem II }\end{array}$ \\
\hline VDAC & Voltage dependent anion channel \\
\hline V-type ATPase & Vacuolar-type ATPase \\
\hline
\end{tabular}

Introduction

As the first non-seed plant with a completely sequenced genome (Rensing et al. 2008) the moss Physcomitrella 
patens has been established as a plant system to investigate the evolution of stress adaptation (Frank et al. 2007; Khandelwal et al. 2010) and of signalling events (Heintz et al. 2004, 2006) in early land plants. Along with these studies a wide range of high-throughput molecular biology tools has been developed and implemented in recent years (Richardt et al. 2007, 2010) paving the way for the use of this model organism for systems biology studies (Decker et al. 2006).

Focussing on plant organelles in a moss such as $P$. patens can be of special interest to obtain information on the evolution of metabolic compartmentalisation (Kopriva et al. 2007; Wiedemann et al. 2010), biosynthetic pathways (Stumpe et al. 2006) and protein sorting mechanisms (Kiessling et al. 2004, Mitschke et al. 2009, Richter et al. 2002). Of special interest are chloroplasts and mitochondria as they are semi-autonomous organelles of endosymbiotic origin with own DNA that encodes only for a small subset of proteins localised to these organelles. Hence, most of the proteins are nuclear-encoded and have to be imported into chloroplasts and mitochondria, respectively (Gray et al. 1999; Reski 2009; Strittmatter et al. 2010). The prediction of sub-cellular protein localisation, however, is error prone because the transit peptides are not well conserved (Bruce 2001) and prediction algorithms are usually trained on the basis of proteins from seed plants. Experimental data sets have shown that the tools currently available for the prediction of sub-cellular localisation can only identify about $50 \%$ of the proteins targeted to organelles (Heazlewood et al. 2004; Kleffmann et al. 2004). These limitations can only be overcome by the generation of species-specific training data sets for the respective organelles, the data sets being very much dependent on the specificity, i.e. correct prediction of the protein localisation (Baginski and Gruissem 2004; Salvi et al. 2008b). The generation of reliable data sets is, however, difficult as contaminations with proteins from other organelles and from the cytosol can never be ruled out during the isolation of single organelles.

Many protocols for the isolation of plant organelles in seed plants are established and have been used for subsequent high-throughput shotgun proteomic studies of Arabidopsis chloroplasts (Kleffmann et al. 2004; Baginski et al. 2005) and mitochondria (Heazlewood et al. 2004; Millar et al. 2001a, b; Sweetlove et al. 2007) or for example, the analysis of mitochondria in rice (Heazlewood et al. 2003; Huang et al. 2009). All these studies employ density gradients for the purification of organelles, sometimes combining it with free flow electrophoresis (FFE) to separate chloroplasts from mitochondria (Eubel et al. 2007; Huang et al. 2009; Lee et al. 2008). However, losses of about $50 \%$ of the organelle material can occur (Eubel et al. 2007), creating a need for the adaptation of existing protocols for each model species (Sweetlove et al. 2007).
For the moss $P$. patens protocols for the isolation of organelles via density gradients have been reported (Kabeya and Sato 2005; Kasten et al. 1997; Marienfeld et al. 1989). However, the moss material used in these experiments was always subjected to protoplastation, which besides from being a laborious and costly pretreatment of the material might also have an effect on the physiological status of the cell and, hence, its proteome.

The aim of this study was to set up a protocol for the simultaneous isolation of highly enriched fractions of pure and intact chloroplasts and mitochondria from protonema tissue of $P$. patens. Integrity and purity of these fractions as well as potential contaminations were assessed using a set of plant compartment marker antibodies. The protocol presented here enables for the isolation of intact chloroplasts and mitochondria and delivers protein yields that are sufficient for sub-cellular proteomic studies in Physcomitrella. Such studies can provide the basis for a large-scale analysis of protein sorting mechanisms in moss and, in addition, unravel the evolution of metabolic and biosynthetic processes occurring in plant organelles.

\section{Materials and methods}

Plant material and growth conditions

Protonema of Physcomitrella patens (Hedw.) Bruch \& Schimp. was cultured in modified liquid Knop medium according to Reski and Abel (1985) containing $250 \mathrm{mg} / \mathrm{l}$ $\mathrm{KH}_{2} \mathrm{PO}_{4}, 250 \mathrm{mg} / \mathrm{l} \mathrm{KCl}, 250 \mathrm{mg} / \mathrm{l} \mathrm{MgSO}_{4} \times 7 \quad \mathrm{H}_{2} \mathrm{O}$, $1,000 \mathrm{mg} / \mathrm{l} \mathrm{Ca}\left(\mathrm{NO}_{3}\right)_{2} \times 4 \mathrm{H}_{2} \mathrm{O}$ and $12.5 \mathrm{mg} / \mathrm{l} \mathrm{FeSO} \mathrm{F}_{4} \times$ $7 \mathrm{H}_{2} \mathrm{O}$ (pH 5.8).

Protonema filaments were disrupted with an UltraTurrax (IKA, Staufen, Germany) at 18,000 rpm for $90 \mathrm{~s}$ before inoculation. Round-bottom flasks containing 51 of medium were inoculated with $0.3 \mathrm{~g}$ dry weight and aerated with $0.3 \mathrm{vvm}$ at $25^{\circ} \mathrm{C}$ under long day conditions $[16 \mathrm{~h}$ light, $8 \mathrm{~h}$ dark, Osram TLD $\left.36 \mathrm{~W} / 25,70 \mu \mathrm{mol} /\left(\mathrm{m}^{2} \mathrm{~s}\right)\right]$. After 7 days, moss was harvested and filter-dried using a vacuum pump and a Büchner funnel.

\section{Organelle isolation}

All following steps were performed at $4^{\circ} \mathrm{C}$ and, where applicable, on wet ice. Typically, two 51 flasks were used per experiment, which corresponds to $20 \mathrm{~g}$ fresh weight of moss. The vacuum filtrated protonema was chopped in organelle isolation buffer [1\% (w/v) polyvinylpolypyrrolidone (PVPP), $300 \mathrm{mM}$ D-sorbitol, $50 \mathrm{mM}$ HEPES, $2 \mathrm{mM}$ Na-EDTA, $1 \mathrm{mM} \mathrm{MgCl}_{2}$ and $\left.0.1 \% \mathrm{BSA}\right]$ in the presence of a protease inhibitor $[0.1 \%(\mathrm{v} / \mathrm{v})$ Sigma Plant Protease Inhibitor Cocktail P 9599] using a household vegetable 
chopping device. After 100-150 strokes with this device the chopped moss was filtered through 3 layers of Miracloth (Calbiochem). The filtrate was transferred to a $50 \mathrm{ml}$ centrifuge tube (Oak Ridge, Nalgene) and the chloroplasts were pelleted at $1,500 \times g$ for $10 \mathrm{~min}$ (Beckman Coulter Avanti Centrifuge J-25, fixed angle rotor Ja 25.50). The supernatant was decanted into new centrifuge tubes and used for the isolation of mitochondria (see below).

A workflow diagram outlining the isolation protocol is given in Fig. 1.

\section{Chloroplast isolation}

The crude chloroplast pellet was resuspended in $3 \mathrm{ml}$ resuspension buffer (300 $\mathrm{mM}$ D-sorbitol, $50 \mathrm{mM}$ HEPES, $2 \mathrm{mM} \mathrm{Na}$-EDTA, $1 \mathrm{mM} \mathrm{MgCl}_{2}$ and $0.1 \% \mathrm{BSA}$ ) using a fine paint brush. The resuspended sample was carefully loaded onto several Percoll density gradients (top to bottom: $5 \mathrm{ml}$ 10\% Percoll, $5 \mathrm{ml} \mathrm{40 \%} \mathrm{Percoll,} 5 \mathrm{ml} \mathrm{80 \%} \mathrm{Percoll)} \mathrm{prepared}$ in resuspension buffer. The Percoll gradients were centrifuged for $20 \mathrm{~min}$ at $16,000 \times \mathrm{g}$. Broken chloroplasts accumulated at the 10-40\% interface, while intact chloroplasts formed a band at the $40-80 \%$ interface. The fractions containing intact chloroplast were collected and combined using a thin glass pipette. The chloroplasts were washed twice with three volumes of washing buffer $(300 \mathrm{mM}$ D-sorbitol, $50 \mathrm{mM}$ HEPES, $2 \mathrm{mM}$ Na-EDTA, $1 \mathrm{mM}$ $\mathrm{MgCl}_{2}$ ) and centrifuged for $10 \mathrm{~min}$ at $1,500 \times \mathrm{g}$. Organelle purity was monitored via fluorescence microscopy. Pellets were frozen at $-80^{\circ} \mathrm{C}$.

\section{Mitochondria isolation}

Mitochondria were purified from the $1,500 \times g$ supernatant adapting a protocol of Kabeya and Sato (2005) using differential centrifugation and a Percoll density gradient. The supernatant was centrifuged at $3,000 \times g$ for 5 min followed by $6,000 \times g$ for $5 \mathrm{~min}$ in the same tube in order to pellet nuclei and cellular debris. Afterwards the resulting supernatant was decanted to a new tube and centrifuged at $18,000 \times g$ for 20 min yielding a greenish pellet enriched in mitochondria.

The pellet was carefully resuspended in $1 \mathrm{ml}$ of washing buffer using a fine paint brush. Several pellets were combined in a potter (Braun, Melsungen, Germany) to a final volume of $4.8 \mathrm{ml}$ and homogenised with 10 strokes. Subsequently $100 \%$ Percoll was added to the sample to a final concentration of $20 \%$.
Fig. 1 Workflow of the isolation of chloroplasts and mitochondria. Schematic illustration of the different steps during the simultaneous isolation of chloroplasts and mitochondria from moss protonema. After cell disruption, filtration and the first centrifugation step, intact and highly enriched chloroplasts and mitochondria can be isolated from the pellet and the supernatant, respectively, using further differential centrifugation and Percoll density gradients

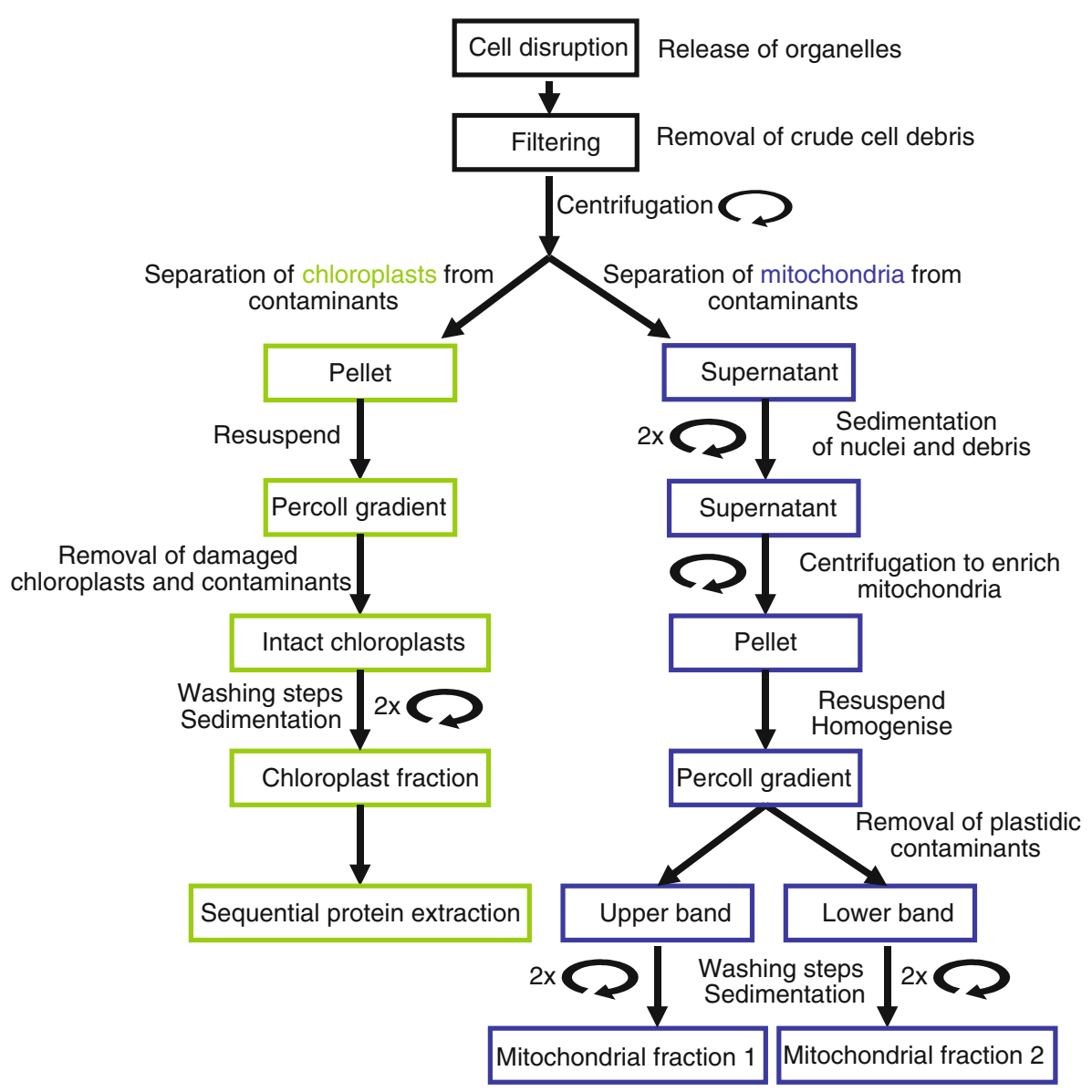


A stepwise Percoll density gradient was assembled by overlaying $5 \mathrm{ml}$ of $80 \%$ Percoll in washing buffer with $5 \mathrm{ml}$ of $33 \%$ Percoll in washing buffer. The homogenised sample in $20 \%$ Percoll was transferred on top of this gradient and centrifuged at $18,000 \times g$ for $1 \mathrm{~h}$.

Two pale whitish mitochondrial bands were extracted at the $20-33 \%$ interface and the 33-80\% interface, respectively. They are subsequently referred to as bands M1 and M2. Mitochondria were carefully collected using thin glass pipettes and freed of Percoll by adding $15 \mathrm{ml}$ of washing buffer, gentle mixing and centrifugation at $18,000 \times g$ for $20 \mathrm{~min}$ (slow deceleration), repeated twice. The upper band yielded a still greenish, loose mitochondria pellet whereas the lower band formed a stable whitish pellet also containing residual PVPP. Pellets were frozen at $-80^{\circ} \mathrm{C}$.

\section{Protein extraction}

Proteins were extracted from frozen organelle pellets and from frozen protonema using lysis buffer $(7.5 \mathrm{M}$ urea, $2.5 \mathrm{M}$ thiourea, $12.5 \%$ glycerol, $62.5 \mathrm{mM}$ tris- $\mathrm{HCl}, 2.5 \%$ n-octylglycosid, $1.25 \mathrm{mM}$ protease inhibitor) and subsequently precipitated with methanol/chloroform (modified after Wessel and Flügge 1984). The protein pellet was resuspended in urea buffer ( $6 \mathrm{M}$ urea, $25 \mathrm{mM}$ bis-tris, $0.2 \%$-octylglucopyranosid, $\mathrm{pH} 8.5)$, measured with a nanodrop (Thermo Scientific) and mixed with SDS sample buffer (Bio-Rad) for SDS-PAGE. The measured protein concentration was confirmed by Coomassie (Fermentas PageBlue) staining of SDS gels. Supplementary Fig. 1 shows an example of a silver-stained SDS-PAGE equally loaded with $4 \mu \mathrm{g}$ organellar protein extracts prepared using lysis buffer.

Sequential chloroplast protein extraction was performed after a protocol adapted from Molloy et al. (1998) to obtain a soluble fraction (Cs) and a chloroplast membrane fraction $(\mathrm{Cm})$. Frozen chloroplast pellets were resuspended in up to $500 \mu \mathrm{l}$ chloroplast protein extraction buffer I [CPE I; $2.5 \mathrm{mM}$ EDTA, $5 \mathrm{mM} \mathrm{MgCl}_{2}, 10 \mathrm{mM} \mathrm{KCl}, 20 \mathrm{mM}$ HEPES, 300 mM D-sorbitol, 1\% (w/v) PVPP, 0.1\% (v/v) plant protease inhibitor] followed by subsequent incubation in an ultrasonic ice bath for $20 \mathrm{~min}$. The supernatant was collected after centrifugation $\left(20 \mathrm{~min}, 4^{\circ} \mathrm{C}, 20,000 \times g\right)$ representing fraction Cs. The residual green pellet was resuspended in up to $500 \mu \mathrm{CPE}$ II [CPE I with $1 \%(\mathrm{v} / \mathrm{v})$ Triton-X 100], followed by a subsequent incubation in an ultrasonic ice bath for $20 \mathrm{~min}$. The supernatant was collected, representing fraction $\mathrm{Cm}$.

The soluble total protein fraction (Ts) was prepared using Tris-buffer [40 mM tris-(hydroxymethyl)-aminomethane, $0.5 \%(\mathrm{w} / \mathrm{v})$ PVPP, $1 \%(\mathrm{v} / \mathrm{v})$ plant protease inhibitor]. Frozen protonema $(500 \mathrm{mg})$ was homogenised with mortar and pestle and thawed in the presence of Tris-buffer. The homogenate was incubated for $20 \mathrm{~min}$ in an ultrasonic ice bath. Subsequently the homogenate was centrifuged for $90 \mathrm{~min}$ at $121,000 \times g$ (Beckman Coulter Optima L-60, rotor type $\mathrm{Ti} 70.1)$ at $2^{\circ} \mathrm{C}$. The clear supernatant was transferred into Teflon-centrifuge tubes (Oak-Ridge, Nalgene) and precipitated overnight with five volumes of acetone with $0.2 \%$ dithiothreitol (DTT) at $-20^{\circ} \mathrm{C}$. Afterwards the proteins were pelleted at $12,000 \times g$ for $10 \mathrm{~min}$ and $0^{\circ} \mathrm{C}$. The protein pellet was resuspended in $20 \mathrm{ml}$ acetone with $0.2 \%$ DTT and incubated for $1 \mathrm{~h}$ at $-20^{\circ} \mathrm{C}$. After centrifugation as described above, the air-dried protein was resuspended in lysis buffer [8 M urea, 4\% 3((3-cholamidopropyl)-dimethylammonio)propansulfat, $100 \mathrm{mM}$ DTT, $40 \mathrm{mM}$ Tris-(hydroxylmethyl)aminomethane]. Protein concentration of the fractions was determined via Bradford assay (Bradford 1976) and mixed with SDS sample buffer (Bio-Rad) for SDS-PAGE.

\section{Western blotting}

After gel electrophoresis using ready-made SDS-gels (Ready gels, $12 \%$ Tris-HCl, Bio-Rad), the stacking gel was cut off and discarded. The remaining gel was immersed in $100 \mathrm{ml}$ cathode-buffer [25 mM tris, $40 \mathrm{mM}$ glycine, $10 \%$ (v/v) methanol] for $15 \mathrm{~min}$. Transfer membranes (Immobilon-P, Millipore) were incubated in $100 \%$ methanol for $15 \mathrm{~s}$, washed for $2 \mathrm{~min}$ in water and subsequently equilibrated for at least $5 \mathrm{~min}$ in $100 \mathrm{ml}$ anode-buffer II [25 mM Tris, $10 \%(\mathrm{v} / \mathrm{v})$ methanol]. Six pieces of filter paper (Grade GB003, Whatman) in the size of the membranes were incubated as follows: three in $100 \mathrm{ml}$ cathode-buffer, two in $100 \mathrm{ml}$ anode-buffer I [0.3 M Tris, $10 \%(\mathrm{v} / \mathrm{v})$ methanol] and one together with the membrane in $100 \mathrm{ml}$ anodebuffer II (filter paper on top and membrane below the paper).

The transfer sandwich was placed and assembled directly on the anode-plate of the semi-dry blotting device (Trans-Blot SD Semi-dry transfer cell, Bio-Rad). Assembly of the transfer sandwich from anode to cathode: two filter papers with anode-buffer I, one filter paper with anodebuffer II, membrane, separating gel and three filter papers with cathode-buffer. Transfer was performed at $1.2 \mathrm{~mA} / \mathrm{cm}^{2}$ for an hour.

Membranes were blocked with $4 \%$ blocking reagent (ECL Advance, GE Healthcare) in TBST [20 mM Tris$\mathrm{HCl}, \mathrm{pH} 7.6,137 \mathrm{mM} \mathrm{NaCl}, 0.1 \%$ (v/v) Tween 20] for an hour. Membranes were washed five times: two short immersions, then a $15 \mathrm{~min}$ wash followed by two $5 \mathrm{~min}$ washing steps. Incubation with primary antibodies was performed at room temperature for an hour followed by the previously described washing procedure. The final concentration for the primary antibody was determined 
empirically for each antibody (see Table 1 for details). Membranes were incubated with the secondary antibody (anti-rabbit HRP-conjugate, Amersham) at a final concentration of 1:500,000 followed by washing steps. Reactive bands were detected using ECL detection (ECL Advance detection kit, GE Healthcare).

\section{Antibody production}

Polyclonal antibodies were raised in rabbits against KLHconjugated peptides derived from conserved regions of the target protein across a range of species including monoand dicotyledonous plants and P. patens or Chlamydomonas reinhardtii. The antibodies were validated using available positive and negative controls. A summary of antibody names, full names of their target proteins, predicted protein localisations, UniProt or TAIR accession numbers, organism of origin and expected/apparent molecular weights is given in Table 1 .

\section{Fluorescence microscopy}

To stain mitochondria and verify mitochondrial integrity $200 \mu 1$ of mitochondrial fractions (M1 and M2) were taken from the density gradient and stained with $200 \mathrm{nM}$ MitoTracker Green FM and MitoTracker Red CMXRos (Molecular Probes), respectively, in washing buffer. After 15 min of gentle shaking at room temperature, samples were observed under a fluorescence microscope (Axioplan, Zeiss, Jena, Germany) using a bandpass $450-490 \mathrm{~nm}$ excitation filter with a $520 \mathrm{~nm}$ long-pass emission filter for MitoTracker Green FM stained samples and a bandpass 546/12 excitation filter with a 590 long-pass emission filter for MitoTracker Red CMXRos stained samples.

\section{Results}

Protein yield

Simple chopping of moss protonema yielded a cell homogenate that can be easily and rapidly fractionated for the simultaneous isolation of chloroplasts and mitochondria via differential centrifugation and Percoll density gradients (Fig. 2a, b). Twenty gram fresh weight of moss material (corresponding to $2 \mathrm{~g}$ dry weight) yielded protein amounts of 3-5 mg chloroplast protein and 60-100 $\mu \mathrm{g}$ mitochondrial protein, i.e. $150-250 \mu \mathrm{g}$ of chloroplast protein and 3-5 $\mu \mathrm{g}$ mitochondrial protein per gram of fresh weight of moss material. After isolation, organelle pellets were frozen and the proteins from the respective pellets extracted for subsequent experiments.
Purity and integrity of mitochondria

Two distinct whitish bands were observed in the Percoll density gradient during purification of mitochondria, one at the 20-33\% interface (M1) just below the green band of chloroplast debris and another one at the 33-80\% interface (M2) (Fig. 2b). Samples from both bands were analysed by fluorescence microscopy and the presence of mitochondria was confirmed by MitoTracker Green staining (Supplementary Fig. 2a, b). Additional staining with MitoTracker Red CMXRos confirmed the existence of a membrane potential (Supplementary Fig. 2c, d).

Impurities in the mitochondrial fraction were assessed using antibodies against plastidic contaminants, namely, the membrane localised light-harvesting complex II type II chlorophyll $a / b$-binding protein (Lhcb2) and the plastidic stroma localised glutamine synthetase (GLN1/GLN2), and antibodies against Golgi apparatus and tonoplast membrane contaminants, namely, the ADP-ribosylation factor 1 (Arf1) and the Epsilon subunit of the tonoplast H+ ATPase (V-type ATPase) localised in Golgi and tonoplast, respectively (Fig. 3).

Immunoblot signals for the mitochondrial fraction from the $20-33 \%$ interface (M1) were weak for plastidic markers and absent for Golgi vesicle and tonoplast markers (Fig. 3a, b, f, g), while the mitochondrial fraction from the 33-80\% interface (M2) showed only a weak positive signal for contamination with Golgi vesicles (Fig. 3f).

The signal strength for the three mitochondrial marker antibodies used, the plant alternative oxidase 1 and 2 (AOX1/2) and the cytochrome $c$ oxidase subunit 2 (COX II) which are both localised in the inner mitochondrial membrane, and the antibody against the voltage-dependent anion-selective channel protein 1 (VDAC1), a protein of the outer mitochondrial membrane, was higher for the mitochondrial protein extracts from the M1 fraction (Fig. 3c, d). Integrity of the mitochondria of both fractions was confirmed by the positive immunoblot signal for VDAC1 (Fig. 3d).

Purity of chloroplasts

During the purification in the Percoll density gradient, the intact chloroplasts accumulated at the $40-80 \%$ interface, while the broken chloroplasts were found at the 10-40\% interface (Fig. 2a).

To detect impurities in the chloroplast fraction (C) the same set of antibodies as for the mitochondrial fraction was used (Fig. 3). Immunoblots showed that the chloroplasts were free of contamination by Golgi (Fig. 3f) but were contaminated to some extent with tonoplast membranes (Fig. 3g). The signal strength of the mitochondrial marker antibodies against chloroplast proteins varied strongly. The 


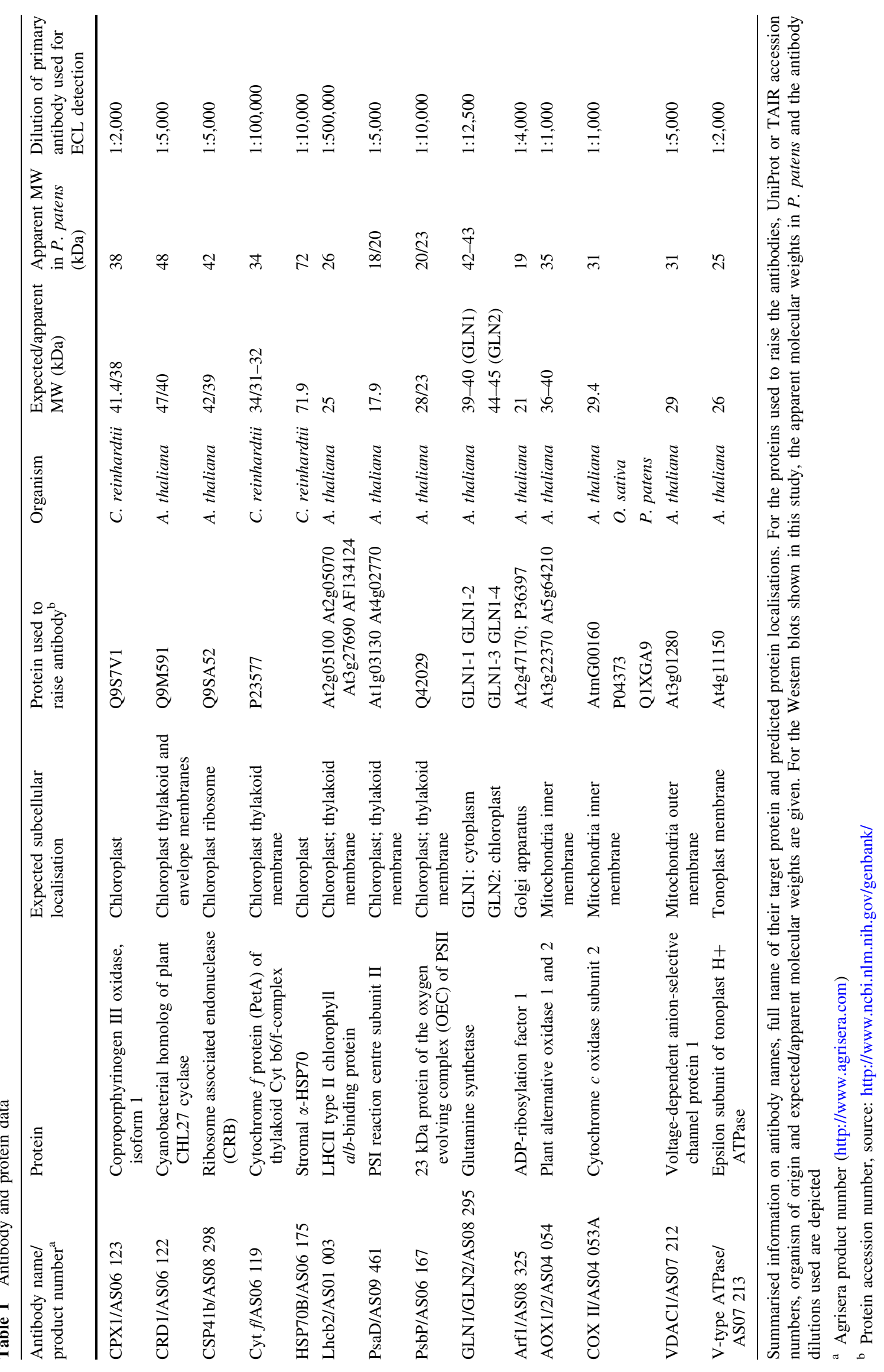



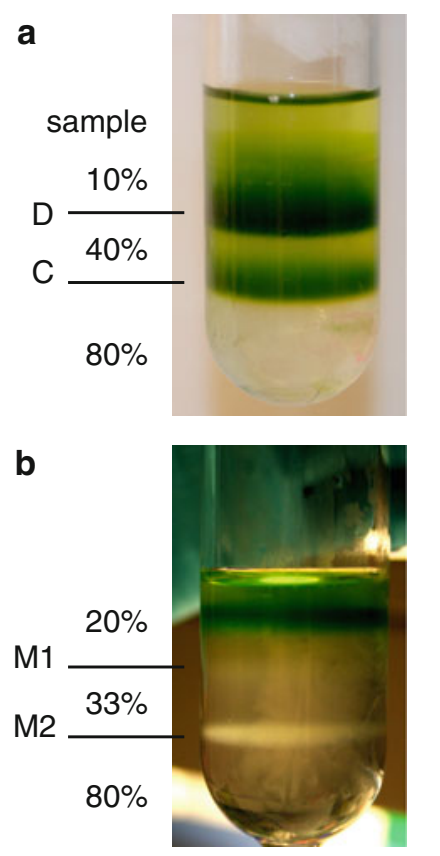

Fig. 2 Percoll gradients after centrifugation. Percentages of Percoll in buffer are given for the different layers. a Purification of intact chloroplasts, $D$ debris, $C$ intact chloroplasts $\mathbf{b}$ Purification of mitochondria, M1 mitochondrial fraction 1, M2 mitochondrial fraction 2; the greenish band in the upper part of the gradient consists of chloroplast debris

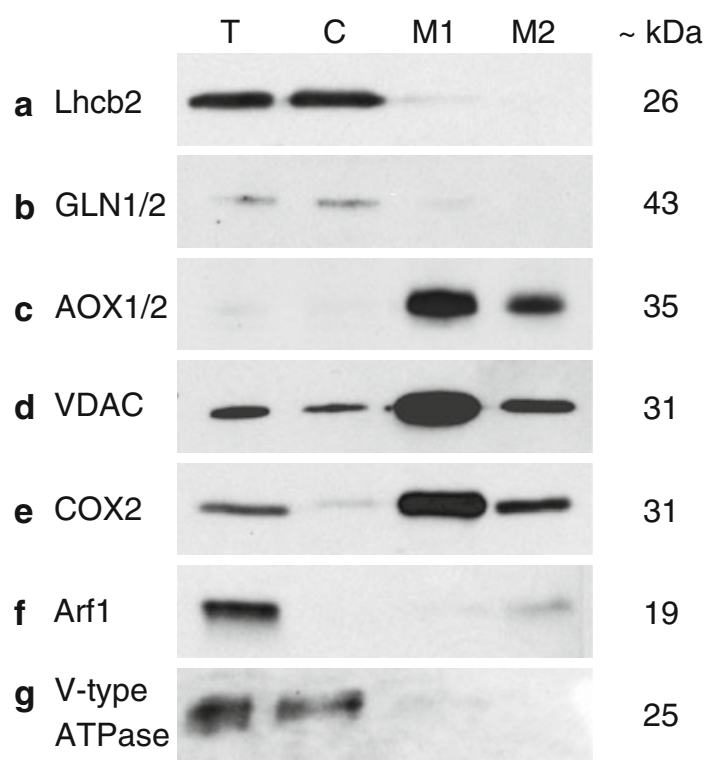

Fig. 3 Immunoblots assessing the organellar purity of urea-extracted proteins. $T$ total protein, $C$ chloroplast protein, $M 1$ mitochondrial fraction 1 protein, $M 2$ mitochondrial fraction 2 protein, loading amounts: $10 \mu \mathrm{g} / \mathrm{lane}(\mathbf{a}, \mathbf{e}), 2.5 \mu \mathrm{g} / \mathrm{lane}(\mathbf{b}-\mathbf{d}, \mathbf{f}, \mathbf{g}$ ); for dilutions of primary antibodies, see Table 1

AOX1/2 antibody gave no signal whereas the signal for COX II was weak and the one for VDAC1 was clear (Fig. 3c-e). The immunoblot signals were all at the

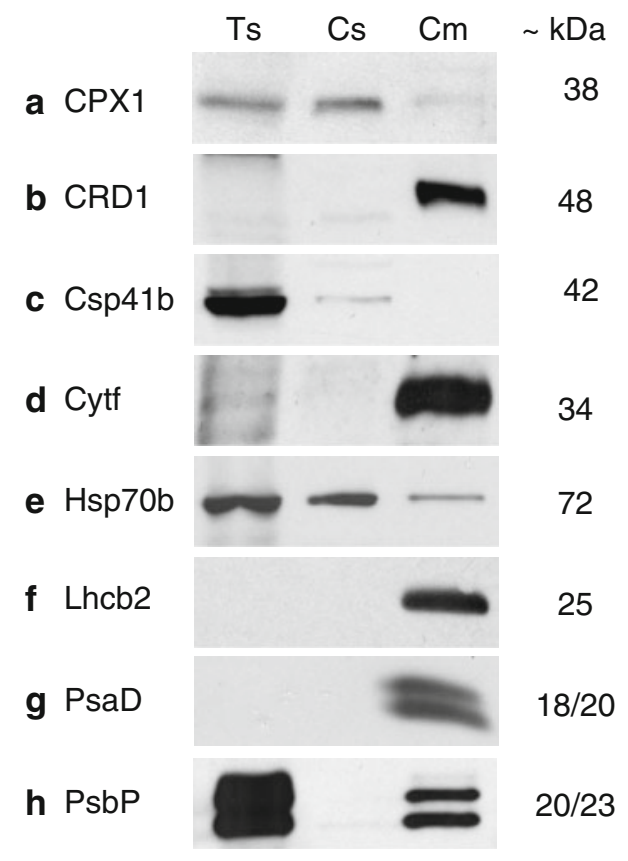

Fig. 4 Immunoblots from sequentially extracted proteins of chloroplasts. Ts total soluble protein, $\mathrm{Cs}$ chloroplast soluble protein, $\mathrm{Cm}$ chloroplast membrane protein; loading amounts: $5 \mu \mathrm{g} / \mathrm{lane}$; for dilutions of primary antibodies, see Table 1

expected size as indicated by the manufacturer. The total protein extract $(\mathrm{T})$ used as a control showed clear signals for each of the antibodies tested besides from the AOX1/2, which was very weak (Fig. $3 \mathrm{a}-\mathrm{g}$ ).

The success of the organelle isolation procedure was further assessed for chloroplast proteins via the application of a series of chloroplast specific antibodies against the sequentially extracted soluble (Cs) and membrane proteins (Cm) from intact chloroplasts (Fig. 4).

All the antibodies against chloroplast proteins not localised to the membranes, i.e. the coproporphyrinogen III oxidase, isoform 1 (CPX1), the ribosome associated endonuclease (CSP41b) and the stromal heat-shock protein (Hsp70b), showed a clear signal in the soluble chloroplast protein fraction whereas for the proteins extracted from the membrane fraction only the CPX1 and the Hsp70b resulted in a very weak and a weak signal, respectively (Fig. 4a, c, e).

Immunoblot signals for the antibodies against proteins localised to the chloroplast membranes, namely, the cyanobacterial homolog of the plant CHL27 cyclase (CRD1), the cytochrome $f$ protein of the thylakoid Cyt b6/ f-complex (Cyt $f$ ), the light-harvesting complex II type II chlorophyll a/b-binding protein (Lhcb2), the photosystem I reaction centre subunit II (PsaD) and the $23 \mathrm{kDa}$ protein of the oxygen evolving complex of the photosystem II (PsbP) were all very strong in the protein extract from the chloroplast membrane fraction (Fig. 4b, d, f-h). For both 
antibodies, PsaD and PsbP, two signals were obtained, namely, at 18 and $20 \mathrm{kDa}$ for PsaD and at 20 and $23 \mathrm{kDa}$ for PsbP. None of these five antibodies against membrane proteins of the chloroplast delivered a signal in the protein extracts of the chloroplast soluble fraction. For the protein extracts from the soluble total protein sample (Ts) immunoblot signals were obtained for all the proteins not localised to the membranes (CPX1, CSP41b, Hsp70b) (Fig. 4a, c, e). No signal was obtained for the membrane localised chloroplast proteins, besides for PsbP with which two highly saturated signals were recorded (Fig. 4h).

\section{Discussion}

Protein yield

Previous publications using mitochondria for proteomic studies (Heazlewood et al. 2004; Kruft et al. 2001; Millar et al. 2001a, b) did not indicate the amount of mitochondrial protein recovered per gram of fresh weight of starting material. It is certain that in moss a reduced amount of starting material is available as compared to seed plants. However, the optimised cultivation of moss protonema in aerated liquid culture allows for a yield of $60-100 \mu \mathrm{g}$ mitochondrial protein per isolation. The protein yield from isolated chloroplasts is well in the range of previously reported studies. While Kley et al. (2010) reported a range of 149-499 $\mu \mathrm{g}$ Arabidopsis chloroplast proteins per gram of rosette leaves, Salvi et al. (2008a) recovered about $100-150 \mu \mathrm{g}$ protein per gram using $400-500 \mathrm{~g}$ of leaf material. Previous protocols for organelle extraction in moss (Kabeya and Sato, 2005; Marienfeld et al. 1989) did not report protein yield as reference value. Taking into account that the moss material used in this study is derived from a liquid protonema culture, the amount of $20 \mathrm{~g}$ fresh weight of moss and the protein yield extracted from this material are very acceptable to routinely isolate both organellar fractions and perform subsequent proteomics analyses.

Purity and integrity of mitochondria

Surprisingly, the isolation protocol for mitochondria reported here revealed two bands of different densities, indicating two populations of mitochondria in moss protonema. In contrast, Kabeya and Sato (2005) reported only one single band at the $33-80 \%$ Percoll interface. It is possible that the homogenisation step using a potter before the density gradient purification causes disruption of some mitochondria. However, the clear signal in the immunoblot obtained for the mitochondrial outer membrane protein VDAC1 as well as the staining with Mitotracker Red
CMXRos, which stains only intact mitochondria with membrane potential (Gilmore and Wilson 1999; Metivier et al. 1998; Poot et al. 1996) indicate that both mitochondrial fractions contain intact mitochondria. So far, very few reports of a second mitochondrial band in a density gradient exist (Logan et al. 2001; Segui-Simarro et al. 2008). While Logan et al. (2001) found two subpopulations of mitochondria differing in the degree of cristae organisation using electron microscopy techniques on germinating maize embryos, Segui-Simarro et al. (2008) reported for A. thaliana that in meristematic cells two subpopulations of mitochondria coexist. The mitochondria extracted from maize were obtained using a sucrose gradient where the organelles accumulated at a density of $22-28 \%$ sucrose and at a density of $37-42 \%$, the latter "heavy" band being the described and expected one. These authors concluded that the mitochondria accumulating in the "light" fraction were remains of mitochondria that were active in the developing embryo during the maturation phase of seed development (Logan et al. 2001). A comparison of these results with those from $P$. patens would be far-fetched as there are no such developmental stages in moss. Observations by SeguiSimarro et al. (2008) in Arabidopsis were based on reconstructed thin-sections of electron micrographs and not on isolated mitochondria and, hence, have to be considered as an in planta finding. The two different mitochondrial fractions in moss as presented here are isolated from protonema without previous protoplastation, in contrast to the protocol of Kabeya and Sato (2005). Protoplastation may lead to a unification of the cells which in turn could reduce or abolish potential functional or morphological differences between organelles in distinct cell types. To date it is unclear if these two populations of mitochondria originate from mitochondria present in different cell types (as e.g. from caulonema and chloronema cells within the protonema tissue) or from two subpopulations of mitochondria from the same set of cells.

The results from the immunoblot analysis demonstrate that the plastidic contamination of both mitochondrial fractions is minimal or not existent, since the signal from the very abundant light-harvesting complex protein (Lhcb2) is absent in the lower mitochondrial fraction M2 and very weak in the upper mitochondrial band M1. In addition, this difference might be caused by residual contamination due to the green layer of broken cell debris accumulating above the M1 band in the density gradient.

The pronounced increase in signal intensity for the three mitochondrial markers in both mitochondrial protein fractions as compared to the total protein and chloroplast protein extracts, which is best observed for the AOX1/2 immunoblot results, confirms that the protocol besides yielding intact and pure mitochondria delivers a highly enriched fraction of organelles. Interestingly, the signal for 
all mitochondrial markers used is stronger in the newly described M1 fraction which hints to differences in protein content between the mitochondrial fractions.

Potential contaminations of the M2 fraction by Golgi and a closer characterisation of both mitochondrial bands at the level of proteins will have to be analysed in subsequent proteomics studies.

\section{Purity of chloroplasts}

Comparable to Mason et al. (1991), the intact chloroplast fraction isolated from moss protonema accumulated at the 40-80\% Percoll interface. Immunoblot results for the proteins extracted from this fraction suggest that the contamination of the chloroplast fraction with outer mitochondrial membranes represented by the VDAC protein is higher than with inner mitochondrial membrane proteins such as COX II and AOX1/2. The contamination with outer mitochondrial membranes might be caused by an attachment of membrane pieces deriving from broken mitochondria to intact chloroplasts during the isolation. A slight contamination due to the handling procedure cannot be ruled out as the removal of the intact chloroplasts from the density gradient with a Pasteur pipette requires penetrating the broken cell debris layer, which might automatically lead to a residual contamination of the glass pipette surface.

Immunoblotting results with the urea-extracted proteins using the plant compartment marker antibodies indicate that there is a contamination with mitochondria in the chloroplast fraction and vice versa. However, contaminations by the Golgi apparatus are absent while there is a clear signal from contaminants of the tonoplast.

The use of several different chloroplast protein markers clearly demonstrates that the method for extraction of a soluble and a membrane chloroplast protein fraction worked very well. All the proteins reported to be part of the chloroplast stroma resulted in clear immunoblot signals for the soluble protein fraction, whereas none of the membrane-localised chloroplast proteins gave a signal. On the other hand, the proteins extracted from the chloroplast membrane fraction resulted in a clear and strong immunoblot signal. The immunoreactive bands observed for CPX1 and Hsp70b in the chloroplast membrane protein fraction might be the result of contaminations due to handling of samples since during sequential chloroplast protein extraction it is not improbable that residues of the soluble fraction are still present in samples of membrane protein. Therefore, even though a residual contamination of soluble proteins in the membrane fraction is likely, there is no contamination of the soluble fraction with membrane proteins. Our protocol might therefore be used in subsequent studies to specifically analyse the proteins present in the chloroplast stroma and to investigate the proteins of a highly enriched thylakoid membrane protein fraction.

Specific enrichment using the sequential extraction method could be confirmed via the immunoblot results with total soluble proteins. None of the chloroplast membrane protein markers resulted in a signal for the total soluble proteins besides for the membrane localised PsbP.

Interestingly, the anti-PsbP as well as the anti-PsaD antibodies gave two signals in the immunoblot. The expected unique $23 \mathrm{kDa}$ signal for $A$. thaliana matched with the apparent size of one of the bands for the $P$. patens chloroplast membrane protein extract, while the second minor band at $20 \mathrm{kDa}$ had not been expected. Yi et al. (2007) also reported two signals for the PsbP protein from A. thaliana, which is a highly conserved protein in seed plants (Bricker and Burnap 2005; Roose et al. 2007). Although recent findings in A. thaliana have demonstrated that there are two putative genes that encode for PsbP-1 and PsbP-2, respectively, the minor band does not correspond to the PsbP-2 protein because it migrates at significantly lower apparent molecular mass (Goulas et al. 2006).

Similarly, although it has been found in other species such as A. thaliana that there can be a second immunoreactive band at $20 \mathrm{kDa}$, i.e. a slightly higher band than the expected unique $18 \mathrm{kDa}$ band using the PsaD antibody, the origin of this second signal is unclear. The question whether the two signals found here with moss represent processed or modified forms of the proteins remains elusive and might be answered using sequencing techniques.

\section{General remarks and conclusions}

Our protocol for a simultaneous isolation of chloroplasts and mitochondria from the same biological sample offers several advantages as it will facilitate a direct comparison of organelles under identical physiological conditions. Protonema tissue has only few different cell types (Reski 1998) and thus is a rather homogeneous material, well suited for systems biology approaches (Decker et al. 2006). In addition, the rapid protocol using intact tissue rather than protoplasts described here, will promote such studies in $P$. patens. Furthermore, employing this protocol we found two distinct mitochondrial bands, a finding that has not been reported before for moss and will be investigated further.

The use of plant compartment marker antibodies designed for algae or seed-plants in this study supports two main points. On the one hand, it demonstrates that plant antibodies can be used across species if their target sequences are conserved and, on the other hand, it has shown for this study that both organellar fractions are highly enriched with only minor contaminations by other organelles. Both aspects paired with the good protein yields 
obtained from the extractions will allow the analysis of sub-cellular proteomes of this non-flowering plant, thus helping to increase our understanding of the evolution of metabolic compartmentalisation, of biosynthetic pathways and of protein sorting mechanisms in land plants.

Acknowledgments This work was supported by the Excellence Initiative of the German Federal and State Governments (GSC-4, Spemann Graduate School of Biology and Medicine), by the German Federal Ministry of Education and Research BMBF (0313921-FRISYS) and by the MINT-Initiative of the State of Baden-Württemberg. We thank Christine Glockner for technical assistance.

Open Access This article is distributed under the terms of the Creative Commons Attribution Noncommercial License which permits any noncommercial use, distribution, and reproduction in any medium, provided the original author(s) and source are credited.

\section{References}

Baginski S, Gruissem W (2004) Chloroplast proteomics: potentials and challenges. J Exp Bot 55:1213-1220

Baginski S, Kleffmann T, von Zychlinski A, Gruissem W (2005) Analysis of shotgun proteomics and RNA profiling data from Arabidopsis thaliana chloroplasts. J Prot Res 4:637-640

Bradford MM (1976) A rapid and sensitive method for the quantitation of microgram quantities of protein utilizing the principle of protein-dye binding. Anal Biochem 72:248-254

Bricker T, Burnap R (2005) The extrinsic proteins of photosystem II. In: Wydrzynski TJ, Kimiyuki S (eds) Photosystem II: the lightdriven water: plastoquinone oxidoreductase. Springer, Dordrecht, pp 95-120

Bruce BD (2001) The paradox of plastid transit peptides: conservation of function despite divergence in primary structure. Biochim Biophys Acta 1541:2-21

Decker EL, Frank W, Sarnighausen E, Reski R (2006) Moss systems biology en route: phytohormones in Physcomitrella development. Plant Biol 8:397-405

Eubel H, Lee CP, Kuo J, Meyer EH, Taylor NL, Millar AH (2007) Free-flow electrophoresis for purification of plant mitochondria by surface charge. Plant J 52:583-594

Frank W, Baar KM, Qudeimat E, Woriedh M, Alawady A, Ratnadewi D, Gremillon L, Grimm B, Reski R (2007) A mitochondrial protein homologous to the mammalian peripheral-type benzodiazepine receptor is essential for stress adaptation in plants. Plant J 51:1004-1018

Gilmore K, Wilson M (1999) The use of chloromethyl-X-rosamine (Mitotracker red) to measure loss of mitochondrial membrane potential in apoptotic cells is incompatible with cell fixation. Cytometry 36:355-358

Goulas E, Schubert M, Kieselbach T, Kleczkowski LA, Gardestrom P, Schroder W, Hurry V (2006) The chloroplast lumen and stromal proteomes of Arabidopsis thaliana show differential sensitivity to short- and long-term exposure to low temperature. Plant J 47:720-734

Gray MW, Burger G, Lang BF (1999) Mitochondrial evolution. Science 283:1476-1481

Heazlewood JL, Howell KA, Whelan J, Millar AH (2003) Towards an analysis of the rice mitochondrial proteome. Plant Physiol 132:230-242
Heazlewood JL, Tonti-Filippini JS, Gout AM, Day DA, Whelan J, Millar AH (2004) Experimental analysis of the Arabidopsis mitochondrial proteome highlights signaling and regulatory components, provides assessment of targeting prediction programs, and indicates plant-specific mitochondrial proteins. Plant Cell 16:241-256

Heintz D, Wurtz V, High AA, Van Dorsselaer A, Reski R, Sarnighausen E (2004) An efficient protocol for the identification of protein phosphorylation in a seedless plant, sensitive enough to detect members of signalling cascades. Electrophoresis 25:1149-1159

Heintz D, Erxleben A, High AA, Wurtz V, Reski R, Van Dorsselaer A, Sarnighausen E (2006) Rapid alteration of the phosphoproteome in the moss Physcomitrella patens after cytokinin treatment. J Proteome Res 5:2283-2293

Huang S, Taylor NL, Narsai R, Eubel H, Whelan J, Millar AH (2009) Experimental analysis of the rice mitochondrial proteome, its biogenesis, and heterogeneity. Plant Physiol 149:719-734

Kabeya Y, Sato N (2005) Unique translation initiation at the second AUG codon determines mitochondrial localization of the phagetype RNA polymerases in the moss Physcomitrella patens. Plant Physiol 138:369-382

Kasten B, Buck F, Nuske J, Reski R (1997) Cytokinin affects nuclearand plastome-encoded energy-converting plastid enzymes. Planta 201:261-272

Khandelwal A, Cho SH, Marella H, Sakata Y, Perroud PF, Pan A, Quatrano RS (2010) Role of ABA and ABI3 in desiccation tolerance. Science 327:546

Kiessling J, Martin A, Gremillon L, Rensing SA, Nick P, Sarnighausen E, Decker EL, Reski R (2004) Dual targeting of plastid division protein FtsZ to chloroplasts and the cytoplasm. EMBO Rep 5:889-894

Kleffmann T, Russenberger D, von Zychlinski A, Christopher W, Sjolander K, Gruissem W, Baginsky S (2004) The Arabidopsis thaliana chloroplast proteome reveals pathway abundance and novel protein functions. Curr Biol 14:354-362

Kley J, Heil M, Muck A, Svatos A, Boland W (2010) Isolating intact chloroplasts from small Arabidopsis samples for proteomic studies. Anal Biochem 398:198-202

Kopriva S, Fritzemeier K, Wiedemann G, Reski R (2007) The putative moss $3^{\prime}$ phosphoadenosine $5^{\prime}$ phosphosulfate reductase is a novel form of adenosine $5^{\prime}$ phosphosulfate reductase without an iron sulfur cluster. J Biol Chem 282:22930-22938

Kruft V, Eubel H, Jansch L, Werhahn W, Braun HP (2001) Proteomic approach to identify novel mitochondrial proteins in Arabidopsis. Plant Physiol 127:1694-1710

Lee CP, Eubel H, O'Toole N, Millar AH (2008) Heterogeneity of the mitochondrial proteome for photosynthetic and non-photosynthetic Arabidopsis metabolism. Mol Cell Proteomics 7:1297-1316

Logan DC, Millar AH, Sweetlove LJ, Hill SA, Leaver CJ (2001) Mitochondrial biogenesis during germination in maize embryos. Plant Physiol 125:662-672

Marienfeld JR, Reski R, Friese C, Abel WO (1989) Isolation of nuclear, chloroplast and mitochondrial DNA from the moss Physcomitrella patens. Plant Sci 61:235-244

Mason CB, Matthews S, Bricker TM, Moroney JV (1991) Simplified procedure for the isolation of intact chloroplasts from Chlamydomonas reinhardtii. Plant Physiol 97:1576-1580

Metivier D, Dallaporta B, Zamzami N, Larochette N, Susin SA, Marzo I, Kroemer G (1998) Cytofluorometric detection of mitochondrial alterations in early CD95/Fas/APO-1-triggered apoptosis of Jurkat $\mathrm{T}$ lymphoma cells. Comparison of seven mitochondrion-specific fluorochromes. Immunol Lett 61:157-163 
Millar AH, Liddell A, Leaver CJ (2001a) Isolation and subfractionation of mitochondria from plants. Methods Cell Biol 65:53-74

Millar AH, Sweetlove LJ, Giege P, Leaver CJ (2001b) Analysis of the Arabidopsis mitochondrial proteome. Plant Physiol 127:17111727

Mitschke J, Fuss J, Blum T, Höglund A, Reski R, Kohlbacher O, Rensing SA (2009) Prediction of dual targeting to plant organelles. New Phytol 183:224-236

Molloy MP, Herbert BR, Walsh BJ, Tyler MI, Traini M, Sanchez JC, Hochstrasser DF, Williams KL, Gooley AA (1998) Extraction of membrane proteins by differential solubilization for separation using two-dimensional gel electrophoresis. Electrophoresis 19:837-844

Poot M, Zhang YZ, Kramer JA, Wells KS, Jones LJ, Hanzel DK, Lugade AG, Singer VL, Haugland RP (1996) Analysis of mitochondrial morphology and function with novel fixable fluorescent stains. J Histochem Cytochem 44:1363-1372

Rensing SA, Lang D, Zimmer AD, Terry A, Salamov A, Shapiro H, Nishiyama T, Perroud PF, Lindquist EA, Kamisugi Y, Tanahashi T, Sakakibara K, Fujita T, Oishi K, Shin IT, Kuroki Y, Toyoda A, Suzuki Y, Hashimoto S, Yamaguchi K, Sugano S, Kohara Y, Fujiyama A, Anterola A, Aoki S, Ashton N, Barbazuk WB, Barker E, Bennetzen JL, Blankenship R, Cho SH, Dutcher SK, Estelle M, Fawcett JA, Gundlach H, Hanada K, Heyl A, Hicks KA, Hughes J, Lohr M, Mayer K, Melkozernov A, Murata T, Nelson DR, Pils B, Prigge M, Reiss B, Renner T, Rombauts S, Rushton PJ, Sanderfoot A, Schween G, Shiu SH, Stueber K, Theodoulou FL, Tu H, Van de Peer Y, Verrier PJ, Waters E, Wood A, Yang L, Cove D, Cuming AC, Hasebe M, Lucas S, Mishler BD, Reski R, Grigoriev IV, Quatrano RS, Boore JL (2008) The Physcomitrella genome reveals evolutionary insights into the conquest of land by plants. Science 319:64-69

Reski R (1998) Development, genetics and molecular biology of mosses. Bot Acta 111:1-15

Reski R (2009) Challenges to our current view on chloroplasts. Biol Chem 390:731-738

Reski R, Abel WO (1985) Induction of budding on chloronemata and caulonemata of the moss, Physcomitrella patens, using isopentenyladenine. Planta 165:354-358

Richardt S, Lang D, Reski R, Frank W, Rensing SA (2007) PlanTAPDB, a phylogeny-based resource of plant transcription-associated proteins. Plant Physiol 143:1452-1466

Richardt S, Timmerhaus G, Lang D, Qudeimat E, Correa LG, Reski R, Rensing SA, Frank W (2010) Microarray analysis of the moss
Physcomitrella patens reveals evolutionarily conserved transcriptional regulation of salt stress and abscisic acid signalling. Plant Mol Biol 72:27-45

Richter U, Kiessling J, Hedtke B, Decker E, Reski R, Börner T, Weihe A (2002) Two RpoT genes of Physcomitrella patens encode phage-type RNA polymerases with dual targeting to mitochondria and plastids. Gene 290:95-105

Roose JL, Wegener KM, Pakrasi HB (2007) The extrinsic proteins of photosystem II. Photosynth Res 92:369-387

Salvi D, Rolland N, Joyard J, Ferro M (2008a) Purification and proteomic analysis of chloroplasts and their sub-organellar compartments. Methods Mol Biol 432:19-36

Salvi D, Rolland N, Joyard J, Ferro M (2008b) Assessment of organelle purity using antibodies and specific assays: the example of the chloroplast envelope. Methods Mol Biol 432:345-356

Segui-Simarro JM, Coronado MJ, Staehelin LA (2008) The mitochondrial cycle of Arabidopsis shoot apical meristem and leaf primordium meristematic cells is defined by a perinuclear tentaculate/cage-like mitochondrion. Plant Physiol 148:1380 1393

Strittmatter P, Soll J, Bolter B (2010) The chloroplast protein import machinery: a review. Methods Mol Biol 619:307-321

Stumpe M, Bode J, Göbel C, Wichard T, Schaaf A, Frank W, Frank M, Reski R, Pohnert G, Feussner I (2006) Biosynthesis of C9aldehydes in the moss Physcomitrella patens. Biochim Biophys Acta 1761:301-312

Sweetlove LJ, Taylor NL, Leaver CJ (2007) Isolation of intact, functional mitochondria from the model plant Arabidopsis thaliana. Methods Mol Biol 372:125-136

Wessel D, Flügge UI (1984) A method for the quantitative recovery of protein in dilute solution in the presence of detergents and lipids. Anal Biochem 138:141-143

Wiedemann G, Hermsen C, Melzer M, Büttner-Mainik A, Renneberg H, Reski R, Kopriva S (2010) Targeted knock-out of a gene encoding sulfite reductase in the moss Physcomitrella patens affects gametophytic and sporophytic development. FEBS Lett 584:2271-2278

Yi X, Hargett SR, Liu H, Frankel LK, Bricker TM (2007) The PsbP protein is required for photosystem II complex assembly/stability and photoautotrophy in Arabidopsis thaliana. J Biol Chem 282:24833-24841 